\title{
Induced Expression of Sarcotoxin IA Enhanced Host Resistance Against Both Bacterial and Fungal Pathogens in Transgenic Tobacco
}

\author{
Ichiro Mitsuhara, ${ }^{1,2}$ Hiroki Matsufuru, ${ }^{1}$ Masahiro Ohshima, ${ }^{3}$ Hisatoshi Kaku, ${ }^{1}$ Yuki Nakajima, ${ }^{5}$ \\ Norimoto Murai, ${ }^{4}$ Shunji Natori, ${ }^{5}$ and Yuko Ohashi ${ }^{1,2}$ \\ ${ }^{1}$ National Institute of Agrobiological Resources, 2-1-2 Kannondai, Tsukuba City, Ibaraki 305-8602, Japan; \\ ${ }^{2}$ Core Research of Science and Technology (CREST), Japan Science and Technology, 2-3 Surugadai, \\ Kannda, Chiyoda-ku, Tokyo 101-0062, Japan; ${ }^{3}$ Hokuriku National Agricultural Research Station, \\ 1-2-1 Inada, Niigata 943-0154, Japan; ${ }^{4}$ Louisiana State University and LSU Agricultural Center, \\ Baton Rouge 70803-1720, U. S. A.; Institute of Physical and Chemical Research (RIKEN), \\ 2-1 Hirosawa, Wako 351-0198, Japan \\ Accepted 26 April 2000.
}

\begin{abstract}
We demonstrate here that induced expression of sarcotoxin IA, a bactericidal peptide from Sarcophaga peregrina, enhanced the resistance of transgenic tobacco plants to both bacterial and fungal pathogens. The peptide was produced with a modified PR1a promoter, which is further activated by salicylic acid treatment and necrotic lesion formation by pathogen infection. Host resistance to infection of bacteria Erwinia carotovora subsp. carotovora and Pseudomonas syringae pv. tabaci was shown to be dependent on the amounts of sarcotoxin IA expressed. Since we found antifungal activity of the peptide in vitro, transgenic seedlings were also inoculated with fungal pathogens Rhizoctonia solani and Pythium aphanidermatum. Transgenic plants expressing higher levels of sarcotoxin were able to withstand fungal infection and remained healthy even after 4 weeks, while control plants were dead by fungal infection after 2 weeks.
\end{abstract}

Higher plants are known to activate specific self-defense mechanisms when attacked by pathogens or insects. One of the mechanisms is called hypersensitive reaction or response (HR), which enables plant to enclose the pathogen in the infected area by formation of necrotic lesions (Goodman and Novacky 1994). HR induces many defense-related signal molecules such as salicylic acid (SA), ethylene, jasmonic acid, and phytoalexin. HR is also characterized by accumulation of pathogenesis-related (PR) proteins, which are classified to 14 families (van Loon 1999). PR proteins include fungal cell wall-degrading enzymes $(\beta-1,3$-glucanases [PR$2]$ and chitinases [PR-3, -4, -8, -7, -11]), antimicrobial peptides (plant defensins [PR-12], thionins [PR-13], and lipid transfer proteins [PR-14]) and the inhibitor of digestive enzymes (proteinase inhibitors [PR-6]). PR proteins are thought to play positive roles in plant self-defense systems by attacking invading pathogens and insects directly. Overexpression of PR proteins such as PR-1, -2, -3, -5, -12, -13,

Corresponding author: Yuko Ohashi; E-mail: yohashi@abr.affrc.go.jp and -14 in plants has been reported to enhance host resistance against fungal or bacterial diseases (Broglie et al. 1991; Vierheilig et al. 1993; Zhu et al. 1994; Alexander et al. 1993; Datta et al. 1999).

Insects produce antimicrobial peptides as the major defense response to pathogen attacks. Many bactericidal peptides are secreted to hemolymph and directly attack invading pathogens (Boman and Hultmark 1987). Sarcotoxins from Sarcophaga peregrina (Matsumoto et al. 1986) and cecropins from Hyalophora cecropia (van Hoften et al. 1985) belong to a type of antibacterial peptide in which two amphiphilic $\alpha$-helices interact with bacterial cell membrane, causing loss of membrane electrochemical potential (Nakajima et al. 1987). This type of bactericidal peptide has not been detected in plants, while other types of antimicrobial peptide such as PR-12, -13, and -14 proteins have been found in both animals and plants. Thus, we reasoned that introduction of the peptide to plants may confer a new type of antimicrobial activity. Jaynes et al. (1993) and Jia et al. (1993) have reported that expression of cecropin B analog enhanced resistance against bacterial pathogen in transgenic plants. We believe sarcotoxin IA is a better candidate for antibacterial activity, since sarcotoxin IA showed several-fold higher antibacterial activity and broader spectra than cecropin B (Okada and Natori 1984). In fact, sarcotoxin has been shown to exert some of the highest antibacterial activity, comparable to that of antibiotics: minimal inhibitory concentration of sarcotoxin against Escherichia coli is 0.2 to $0.3 \mu \mathrm{M}$, while that of ampicillin against Staphylococcus aureus and that of carbenicillin against Proteus mirabilis is 2.1 to $4.2 \mu \mathrm{M}$ and $355 \mu \mathrm{M}$, respectively (Nakajima et al. 1987; Hejzlar et al. 1969; Kunin 1967).

We previously used a powerful, constitutive promoter to express sarcotoxin IA in transgenic plants and demonstrated the increased host resistance to bacterial infection (Ohshima et al. 1999). Here, we report sarcotoxin IA also has antifungal activity in vitro. We chose an inducible PR1a promoter to express sarcotoxin IA and showed the enhanced resistance of transgenic tobacco plants against both bacterial and fungal pathogens in planta. 


\section{RESULTS}

\section{Construction of vectors for constitutive} and inducible expression.

We constructed a new binary vector, PSS, for both constitutive, basal-level expression and inducible, enhanced-level expression of sarcotoxin IA gene (Fig. 1A, PSS). The inducible gene consisted of the tobacco PR1a promoter (Ohshima et al. 1990), the coding sequence of the signal peptide of the PR1a gene, sarcotoxin IA cDNA for the mature peptide, and the terminator of PR1a gene. A selectable marker gene, Cauliflower mosaic virus (CaMV) 35S::nptII, is located in a headto-head orientation to the PR1a promoter. Transgenic plants with the PR1a::GUS and CaMV 35S::nptII construct in a head-to-head orientation exhibited a considerable level of $\beta$ glucuronidase (GUS) activity in healthy and non-induced leaf and the level was greatly increased by SA treatment (Ohshima et al. 1990). Therefore, the PSS construct should confer dual expression patterns: constitutive basal-level expression, and enhanced-level expression induced by SA treatment and necrotic lesion formation after pathogen infection. The construct PST10 was used in our previous study for the constitutive expression of sarcotoxin IA gene, as shown in the lower part of Figure 1A. The sequence for the signal peptide of PR1a protein appears to play a role in secretion of sarcotoxin to the exterior of the cells (Ohshima et al. 1999).

\section{Induced expression of sarcotoxin IA in transgenic tobacco plants.}

The inducible form of sarcotoxin IA gene in the binary vector PSS was transformed to tobacco via Agrobacterium tumefaciens. Thirty independent lines were selected by kanamycin at $100 \mu \mathrm{g} / \mathrm{ml}$. The presence of the transgene in the kanamycin-resistant plants was confirmed by polymerase chain reaction (PCR) with specific primers for amplification of the coding region of sarcotoxin. These plants were named as PSS lines after the binary vector PSS. Leaf disks of PSS lines were incubated in the solution of $0.5 \mathrm{mM}$ SA for 2 days, and soluble proteins were extracted for protein gel blot analysis. The anti-sarcotoxin IA antibody recognized doublet bands at around $8.2 \mathrm{kDa}$ in transgenic plants but not in nontransformed plants. The monomer size of sarcotoxin IA is expected to be $4.2 \mathrm{kDa}$. When the synthetic sarcotoxin IA peptide was applied to sodium dodecyl sulfate-polyacrylamide gel electrophoresis (SDS-PAGE) directly, we found a major signal at $4.2 \mathrm{kDa}$ and a minor band at $8.2 \mathrm{kDa}$ (Fig. 1B). Thus, this $8.2-\mathrm{kDa}$ signal is likely dimer of sarcotoxin peptide. A similar observation was previously reported in PST10 plants (Ohshima et al. 1999), and confirmed again here (Fig. 1C). Although the reason why the signal for sarcotoxin was found as a doublet band is not known, site-specific degradation or modification of sarcotoxin peptide would be the possible reason. Actually, C-terminal glycine of sarcotoxin was processed to amido residue by extracellular, c-terminal, peptide amidase in insects (Matsumoto et al. 1986).

We chose the PSS41 line as a representative of transgenic lines to be examined further. Sarcotoxin IA was immunologically detectable in intact and non-SA-induced leaves and the expression level increased more than 10-fold 2 days after SA treatment (Fig. 1C). Induced levels of sarcotoxin IA in PSS41 plants were estimated to be about $20 \mu \mathrm{g}$ per $\mathrm{g} \mathrm{FW}$, higher than levels in PST10 (about $2 \mu \mathrm{g}$ per g FW; Fig. 1C). As expected, PR-1 proteins were detectable after SA treatment in PSS41 plant (Fig. 1C, lane 3: +SA), but were not evident without SA treatment (Fig. 1C, lane 1: 0 DAT; and Fig. 1C, lane 2: $-\mathrm{SA}$ ). The basal-level expression of the peptide in non-SA-induced PSS41 leaves might be accounted for by the effect of enhancer elements within the $35 \mathrm{~S}$ promoter adjacent to the PR1a promoter, as described previously (Ohshima et al. 1990; Fukuoka et al., in press).
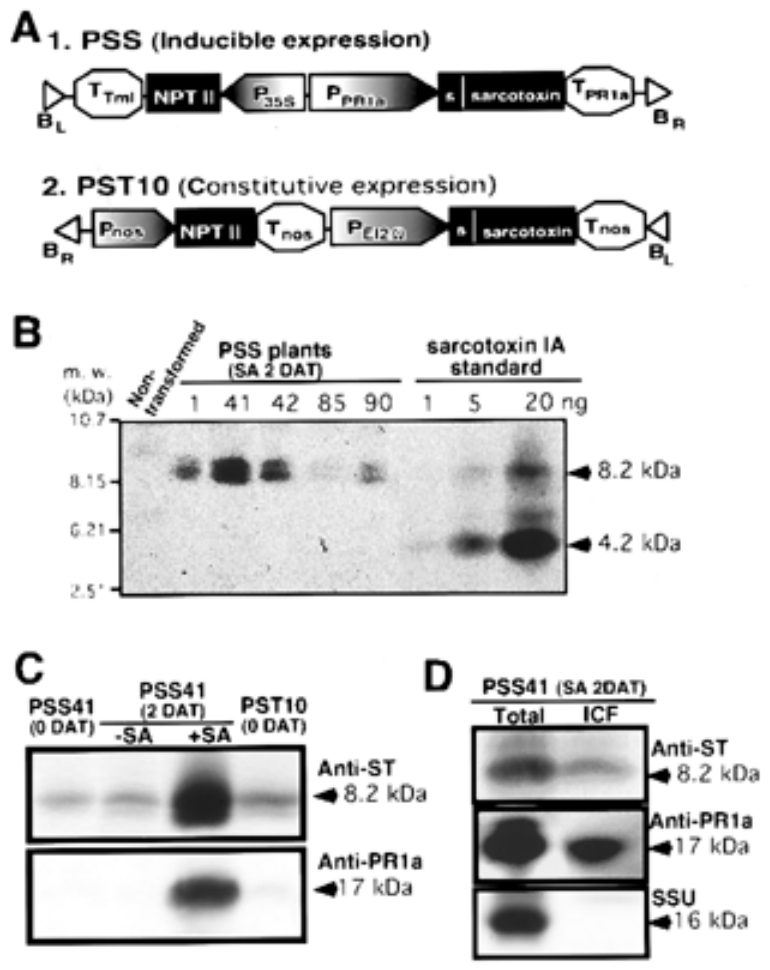

Fig. 1. Structure of the introduced gene. A, Schematic diagram of PSS and PST10. BL and BR, left and right borders of T-DNA of the Agrobacterium tumefaciens Ti plasmid, respectively; PPR1a, the $5^{\prime}$ promoter sequence of the tobacco PR1a gene; s, coding sequence for the signal peptide of PR1a; TPR1a, the $3^{\prime}$ terminator sequence of the tobacco PR1a gene; Sarcotoxin, the coding sequence for the mature sarcotoxin IA; $\mathrm{P} 35 \mathrm{~S}$, the $5^{\prime}$ promoter sequence of the Cauliflower mosaic virus (CaMV) $35 \mathrm{~S}$ transcript; NPTII, coding sequence of the neomycin phosphotransferase II gene; Ttml, 3' terminator sequence of A. tumefaciens tumor morphology large (tml) gene; PEI $2 \Omega$, the promoter of artificial promoter cassette pBE2113 (Mitsuhara et al. 1996); Tnos, The 3' terminator sequence of A. tumefaciens nopalin synthase gene; Pnos, the $5^{\prime}$ upstream sequence of A. tumefaciens nopalin synthase gene. B, Expression of transgene. Leaf disks of five independent PSS transgenic plants were incubated in a $0.5 \mathrm{mM}$ salicylic acid (SA) solution for 2 days. Two days after the treatment (2DAT), crude extracts were prepared and subjected to protein gel blotting with anti-sarcotoxin IA antibody. C, Induced production of the gene products by SA treatment in PSS41 line. Leaf extracts were prepared from fresh leaf disk and leaf disks of PSS41 plant that had been treated with or without $0.5 \mathrm{mM}$ SA for 2 days. For PST10 plant, extract was prepared from fresh leaf disks. Extracts were subjected to protein gel blotting and detected with anti-sarcotoxin antibody (upper panel) or anti-PR1a antibody (lower panel). D, Localization of sarcotoxin in leaves of PSS41 line. Extract from total leaf (Total) and intercellular fluid (ICF) were prepared from leaf disks treated with $0.5 \mathrm{mM}$ SA for 2 days, and subjected to protein gel blotting. Upper panel: signal detected with specific antibody for sarcotoxin IA. Middle panel: PR1 proteins detected with anti-PR1a antibody. Lower panel: small subunit of RuBisCO protein stained with Coomassie brilliant blue R-250. 


\section{Detection of sarcotoxin in the intercellular spaces.}

Intercellular localization of sarcotoxin IA was investigated to understand the predicted role of the PR1a signal peptide. Leaf disks were prepared from fully expanded upper leaves of PSS41 line and incubated in $0.5 \mathrm{mM}$ SA solution for 2 days. The intercellular air spaces of the leaves were replaced by vacuum infiltration with $10 \mathrm{mM}$ sodium phosphate buffer $(\mathrm{pH}$ 7.0) containing protease inhibitors. The intercellular fluid (ICF) was collected by centrifugation and subjected to protein gel blot analysis. As shown in the top panel of Figure 1D, a considerable level of sarcotoxin was detected in the ICF with $15 \%$ recovery compared with total protein extract. On the other hand, extracellular types of PR1 proteins were detected with $50 \%$ recovery (Fig. 1D, middle panel). The absence of small subunit of RuBisCO was detectable in the ICF fraction, suggesting that disruption of intact cells during the vacuuminfiltration procedure was negligible (Fig. 1D, bottom panel).

\section{Enhanced resistance in PSS lines against bacterial infection.}

Leaf disks of 14 independent transgenic lines and nontransformed plants were incubated in suspensions of Erwinia carotovora subsp. carotovora for bacterial soft rot disease (4 $\times 10^{7} \mathrm{CFU}$ per $\mathrm{ml}$ ) at $25^{\circ} \mathrm{C}$. Two days after incubation, nontransformed leaf disks exhibited water-soak symptoms, and maceration and rotting were caused by bacterial infection, while transgenic PSS disks showed resistance to bacterial infection and remained green. The bacterial growth in the immersed solution with the leaf disks of PSS lines 41, 84, 70, 92, $1,90,42,46$, and 37 was significantly lower than that in nontransformed leaf disks (Fig. 2A). Lines PSS41 and 42 were selected as the representative plants with higher resistance against the soft rot disease, and lines PSS10 and 78 were chosen as no or lower resistance plants, respectively. Fully expanded upper leaves of these plants were inoculated with Pseudomonas syringae pv. tabaci for tobacco wild fire disease, and the size of necrotic lesions was compared 10 days after inoculation. Average diameters of necrotic lesions were smaller in PSS 41 and 42 leaves than in PSS10 and 78 leaves and in non-transformed control leaf, suggesting resistance against the infection of $P$. syringae (Fig. 2B). Detectable levels of sarcotoxin after SA treatment were significantly higher in PSS41 and 42 than in PSS78 leaf (Fig. 2C). No sarcotoxin was evident in PSS10 or non-transformed leaves. These observations suggest the higher degree of plant resistance against the bacterial infection may be accounted for by the higher levels of the peptide expressed. Thus, PSS 41 was chosen for further studies as the plant with highest resistance.

Selfed progenies of PSS41 line $\left(\mathrm{T}_{2}\right)$ were selected by kanamycin resistance and grown in a growth chamber. Fully expanded, upper leaves were detached from 5-week-old plants and a $0.5-\mathrm{ml}$ suspension of E. carotovora $\left(2 \times 10^{7} \mathrm{CFU}\right.$ per $\mathrm{ml})$ was absorbed through petioles. Then, the leaves were incubated in a humidity chamber at $28^{\circ} \mathrm{C}$ for 2 days. Leaves of PSS plants remained healthy and free from disease symptom after 2 days (Fig. 2D) and even after 4 days, while leaves of non-transformed plants were wilted and the regions around veins were rotted and exhibited water-soaking symptoms. Figure 2E shows symptoms appeared on leaves of PSS41 and control plants 10 days after $P$. syringae inoculation. No or small confined lesions appeared on leaves of PSS41, while much larger, necrotic lesions around inoculated points were evident on leaves of both $35 \mathrm{~S}:$ GUS and non-transformed control plants.

To compare the amount of pathogen-induced production of sarcotoxin peptide, detached PSS41 leaves were inoculated with $P$. syringae and incubated for 2 days (Fig. 2F). Disks were punched out from the inoculated region (Fig. 2F, "B") and the region $3 \mathrm{~cm}$ apart from the inoculated site (Fig. 2F, "A"), and from noninfected leaf (noninfected) as illustrated in the left panel of Figure 2F. Then, the crude extracts of the disks were subjected to protein gel blot analysis. Sarcotoxin was detected in noninfected leaves, and the level increased by bacterial infection, considerably more in the inoculated disk (Fig. 2F, "B") than in the adjacent, noninoculated disk (Fig. $2 \mathrm{~F}$, "A", right top panel). PR1 proteins were similarly induced after bacterial infection, but not in noninfected leaves (Fig. 2F, bottom panel).

\section{Antifungal activity of sarcotoxin IA in vitro.}

The antifungal activity of the peptide against Rhizoctonia solani, agronomically important pathogenic fungus for sore shin disease, was studied by agar diffusion bioassay. A small disk ( $5 \mathrm{~mm}$ in diameter) was punched out from the mycelium plate and placed at the center of an agar test plate. Then, aliquots containing $0,200,500$, and $1000 \mu$ g each of sarcotoxin were applied to the holes located at the four corners of the plate. Clear zones free from mycelium were formed around the sarcotoxin-containing wells, even though mycelium spread rapidly from the inoculated center to the margin of the agar plate. The size of clear zone increased, corresponding to the higher amount of the peptide applied. As another experiment, growth of the mycelium in the medium containing different concentration of sarcotoxin was monitored (Fig. 3B). Sarcotoxin inhibited the growth of mycelium in a dose-dependent manner, and almost completely abolished the growth at 100 $\mu \mathrm{M}$. Fifty percent inhibitory concentration of the fungal growth $\left(\mathrm{IC}_{50}\right)$ was $12.5 \mu \mathrm{M}$.

The primary target site of sarcotoxin was reported to be the cell membrane of bacteria. To study the inhibitory mechanism of sarcotoxin action to fungus, mycelium of Rhizoctonia solani was incubated in the sarcotoxin solutions ranging from 0 to $100 \mu \mathrm{M}$ for $1 \mathrm{~h}$. Enhanced electrolyte leakage from the mycelium was detected by sarcotoxin treatment in a dosedependent manner, suggesting the peptide damages the membrane integrity of the mycelium (Fig. 3C). The mycelium did not grow at all in the presence of $100 \mu \mathrm{M}$ sarcotoxin, while it grew vigorously without sarcotoxin. The healthy mycelium was stained to dark red with neutral red, which is selectively incorporated into living cells with a normal membrane potential (Schnetkamp et al. 1981). The mycelium was not stained at all after the sarcotoxin treatment (Fig. 3D-2) while non-treated mycelium was stained well, indicating the peptide causes loss of membrane electrochemical potential of the mycelium.

\section{Enhanced plant resistance against fungal pathogens.}

Thirty each of kanamycin-resistant PSS41 plants $\left(\mathrm{T}_{2}\right)$ and control plants containing 35S::GUS gene were transplanted to a $9-\mathrm{cm}$ petri dish containing agar medium (Fig. 4). Then, seven pieces of mycelial plugs of $R$. solani were placed among seedlings at an equal distance from each other. Hyphae 
extended from the mycelial plugs, and reached to all seedlings after 1 day of incubation at $25^{\circ} \mathrm{C}$. After incubation for 2 days, about one-half of PSS41 seedlings remained healthy, while almost all control seedlings started to wilt from the fungal infection. A representative of control 35S::GUS plant exhibiting water-soak-like symptoms and a PSS41 seedling showing no detectable disease symptom are shown in Figure 4A. Cotyle- dons indicated by arrowheads in Figure 4A were fixed, crosssectioned to $15 \mu \mathrm{m}$ in thickness, and photographed after staining by Stoughton's method. In the control cotyledons, hyphae, which are stained dark purple, invaded deeply into cotyledon tissues (Fig. 4B, left). In PSS 41 line, hyphae were also observed on the cotyledon surface. However, they did not penetrate into the leaf tissue (Fig. 4B, right), suggesting trans-

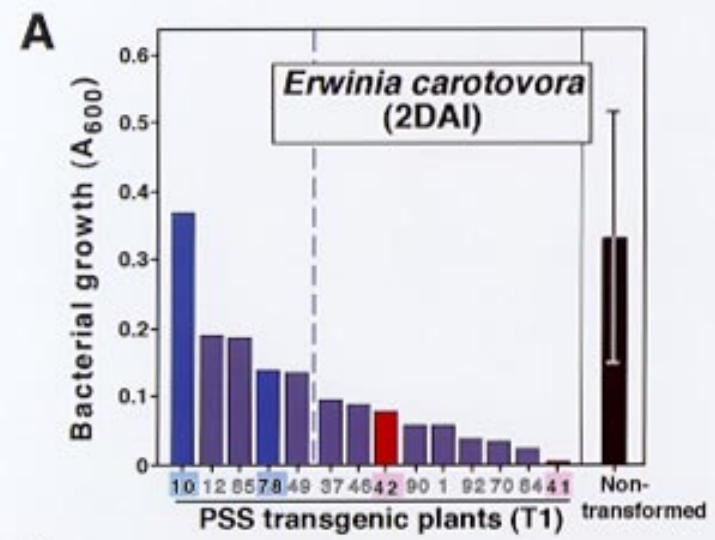

B
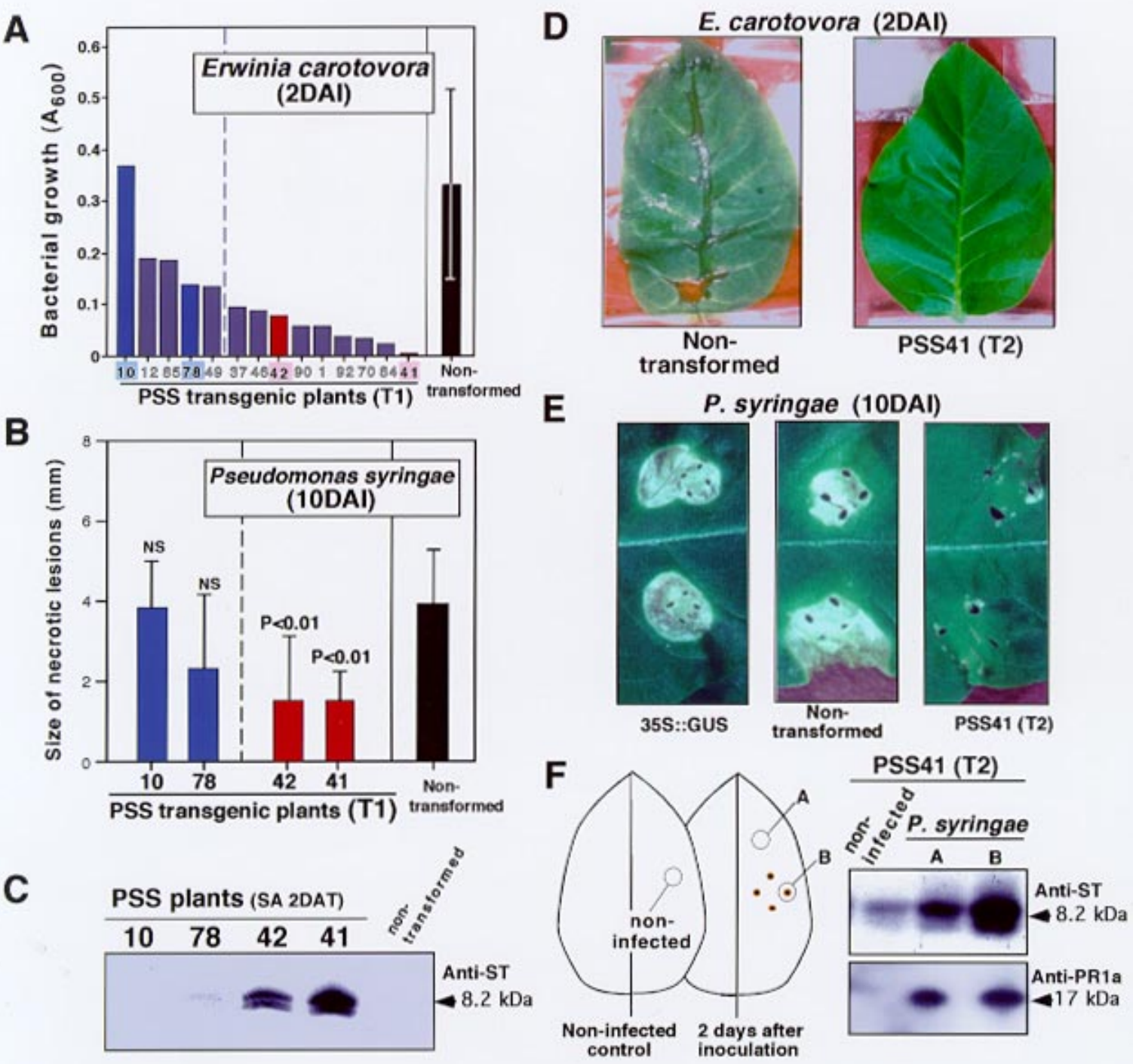

Fig. 2. Enhanced resistance against bacterial pathogen in PSS lines. A, Growth inhibition of Erwinia carotovora in the presence of leaf disks of PSS plants. Three 12-mm-diameter leaf disks were prepared from PSS plants $(20 \mathrm{~cm}$ in height) and incubated in $3 \mathrm{ml}$ of bacterial suspension (E. carotovora, $4 \times 10^{7} \mathrm{CFU}$ per $\mathrm{ml}$ ) for 2 days at $28^{\circ} \mathrm{C}$. Increase in absorbance at $600 \mathrm{~nm}$ of the suspension was determined 2 days after inoculation (2DAI). For nontransformed control plants, mean value from six independent plants was shown with SD. B, Enhanced resistance against infection of Pseudomonas syringae in PSS lines. Fully expanded upper leaves with no (PSS10), slight (PSS78), or higher (PSS41, 42) resistance and non-transformed plants were wounded with needles and subsequently inoculated with P. syringae $\left(2 \times 10^{6} \mathrm{CFU}\right.$ per ml). Diameters of four necrotic lesions were determined at 10 days after inoculation (10DAI), and mean values were shown with SD. Significance of difference with respect to non-transformed plants of each transgenic line is indicated (NS = non-significant). C, Levels of accumulated sarcotoxin in PSS plants. Leaf disks of PSS lines and non-transformed plants were incubated with $0.5 \mathrm{mM}$ salicylic acid (SA), and crude leaf extracts were subjected to protein gel blotting 2 days after treatment with anti-sarcotoxin antibody. D, Enhanced resistance against E. carotovora in PSS41 line. Fully expanded upper leaves of PSS41 (T2) and non-transformed plants (20 cm in height) were detached, and $0.5 \mathrm{ml}$ of bacterial suspension $\left(2 \times 10^{7} \mathrm{CFU}\right.$ per $\left.\mathrm{ml}\right)$ was completely absorbed though petioles. Leaves were then incubated in a humidifying chamber for 2 days at $28^{\circ} \mathrm{C}$. E, Enhanced resistance against $P$. syringae in PSS 41 line. Fully expanded upper leaves of control (35S::GUS), non-transformed, and PSS41 plants $\left(\mathrm{T}_{2}\right)$ were detached and inoculated with bacterial suspension $\left(2 \times 10^{6} \mathrm{CFU}\right.$ per $\left.\mathrm{ml}\right)$ of $P$. syringae, and incubated in a humidifying chamber. Photographs were taken 10 days after inoculation. F, Inducible accumulation of sarcotoxin by bacterial infection in PSS41. Detached leaves of PSS41 plant $\left(\mathrm{T}_{2}\right)$ were wounded with needles and inoculated with P. syringae $\left(2 \times 10^{7} \mathrm{CFU}\right.$ per $\left.\mathrm{ml}\right)$. Leaf disks $7 \mathrm{~mm}$ in diameter were prepared (indicated regions in left panel) at 2 days after inoculation, and subjected to protein gel blot analysis. Non-infected, healthy leaf; A, 3-cm distant part from the inoculated site; B, infected part. Right panel, protein gel blot analysis detected with anti-sarcotoxin antibody (upper panel) and anti-PR1a antibody (lower panel). 
genic plants showed resistance to fungal infection at the early step. To see whether the PR-1a promoter::sarcotoxin fusion gene was activated by fungal infection, $\mathrm{T}_{2}$ seedlings of PSS41 were inoculated with $R$. solani and analyzed by protein gel blotting (Fig. 4C). Sarcotoxin was immunologically detectable at a basal level in four noninoculated seedlings, and the level was increased at 2 days after fungal inoculation.

Figure 4D demonstrates seedlings of kanamycin-resistant PSS41 plants $\left(\mathrm{T}_{2}\right)$ at 15 days after inoculation with the mycelial disks of $R$. solani in agar plates. Five out of 30 seedlings remained green and free from the disease symptom, and eight seedlings were partly compromised by fungal infection. All control seedlings were dead or severely damaged and the color of cotyledons turned from green to white. Twenty-five out of 30 seedlings remained free from disease symptoms after infection with another pathogenic fungus, Pythium aphanidermatum for tobacco damping-off disease (Fig. 4E).
The PSS41 seedlings, which exhibit enhanced tolerance to $R$. solani in Figure 4D, were transplanted to pots and grown in a temperature-controlled growth chamber. Fully expanded, upper leaves of the PSS plants and the control plants were detached and inoculated with mycelial plugs $(3 \times 3 \mathrm{~mm})$ of Phytophthora nicotianae var. nicotianae for tobacco black shank disease. Two days after inoculation, large water-soaklike symptoms were developed around the inoculated site in the control plants, while the areas were considerably smaller in the PSS plants (Fig. 4F). The invasion stopped at 2 or 3 days after inoculation in PSS leaves and the invaded areas were restricted to around $2 \mathrm{~cm}$, while the infected and damaged area expanded to the entire area of control leaf.

\section{DISCUSSION}

There are a number of reasons why the gene for sarcotoxin IA peptide will be an excellent candidate to confer plant re-
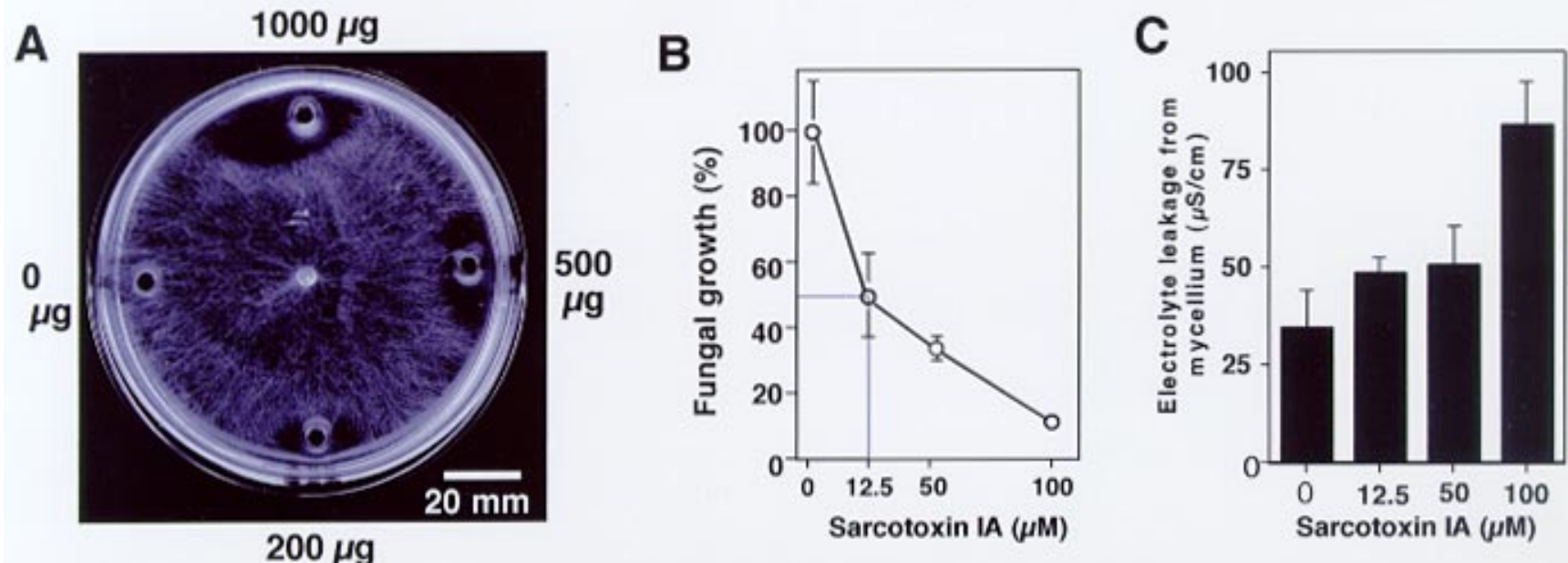

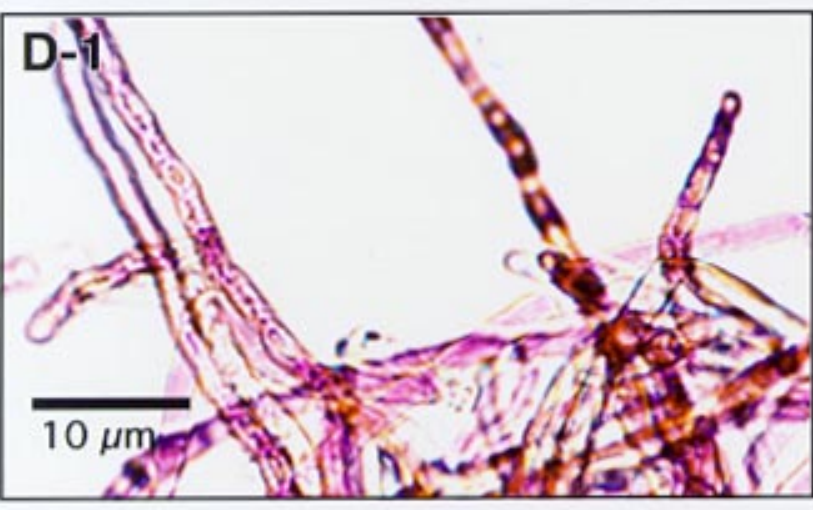

Sarcotoxin $0 \mu \mathrm{M}$

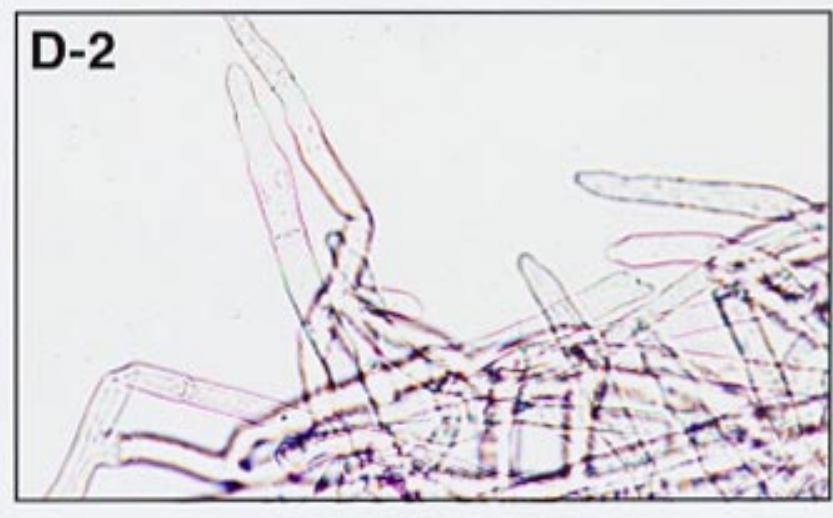

Sarcotoxin $100 \mu \mathrm{M}$

Fig. 3. Antifungal activity of sarcotoxin IA in vitro. A, Suppression of mycelium growth of Rhizoctonia. solani by sarcotoxin IA. Synthetic sarcotoxin IA $(1000,500,200$, and $0 \mu \mathrm{g})$ in a total volume of $50 \mu \mathrm{l}$ was applied to holes in agar plate in a clockwise direction. A disk of the mycelium plate $(3 \mathrm{~mm}$ in diameter) was placed on the center of the agar plate. Photograph was taken $20 \mathrm{~h}$ after incubation at $28^{\circ} \mathrm{C}$. B, Effect of sarcotoxin IA on hyphae growth of $R$. solani. A disk of the mycelium plate was placed on the center of agar plates containing $100,50,12.5$, and $0 \mu \mathrm{M}$ sarcotoxin, respectively. Length of expanded hyphae was determined $12 \mathrm{~h}$ after incubation, expressed as percentages of length to the control plates $(0 \mu \mathrm{M})$. $\mathbf{C}$, Enhanced electrolyte leakage from sarcotoxin-treated mycelium of $R$. solani. Disks of mycelium plates were cultured in potato dextrose broth (PDB) for $16 \mathrm{~h}$. After three washes with water, mycelium was incubated with $0,12.5,50$ and $100 \mu \mathrm{M}$ sarcotoxin solution for $1 \mathrm{~h}$, respectively. Electric conductivity $\left(\mu \mathrm{S} / \mathrm{cm}^{-1} 10^{-6} \Omega^{-1} \mathrm{~cm}^{-1}\right)$ of the solutions before and after incubation was measured. Mean values from three different samples are shown with SD. D, Loss of membrane integrity of $R$. solani mycelium by sarcotoxin treatment. Liquid-cultured mycelium was incubated in the presence (D-2) or absence (D-1) of $100 \mu \mathrm{M}$ sarcotoxin IA for $16 \mathrm{~h}$ and stained with neutral red. Bar $=10 \mu \mathrm{m}$. 
sistance against pathogen infection. First, we demonstrated here that the peptide shows both antibacterial and antifungal activities at nano- and micromolar levels in vitro, respectively. Second, the peptide does not appear to inhibit the growth of plant and animal cells (Ohshima et al. 1999; Matsumoto et al. 1986). Sarcotoxin preferentially disrupts bacterial cell mem-

A

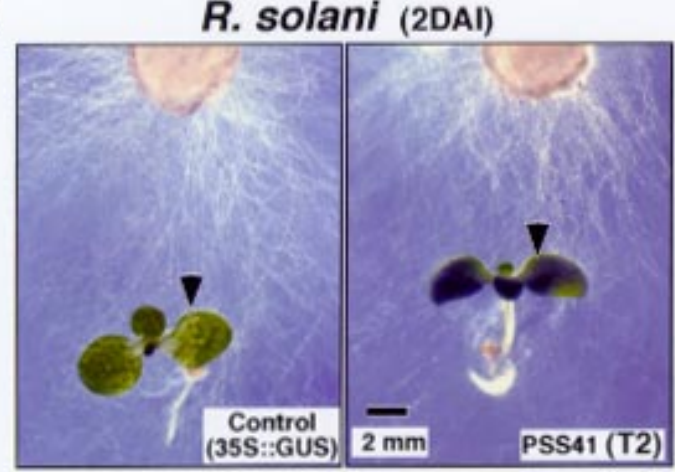

B
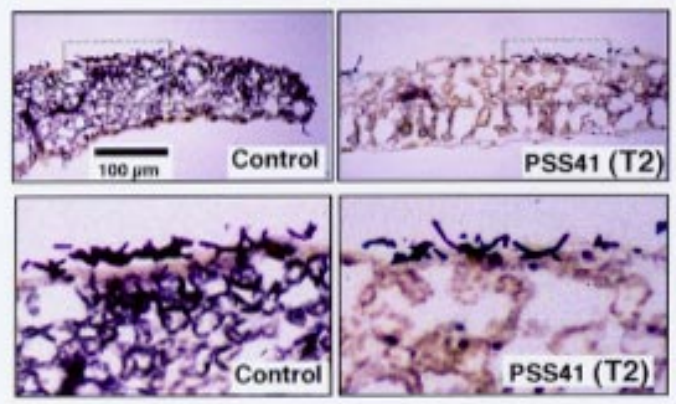

C

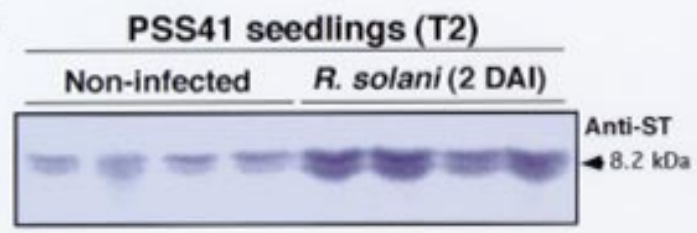

branes that are rich in negatively charged phospholipids. Cell membranes of higher plants and animals contain small amounts of anionic phospholipid (Nakajima et al. 1987). Third, sarcotoxin confers inhibition to a broader spectrum of pathogenic microorganisms, probably because the target of the peptide is the cell membrane and not a specific substrate or
D

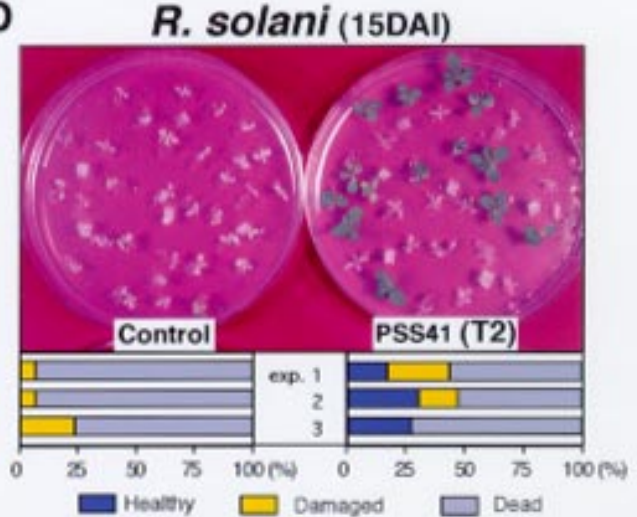

E
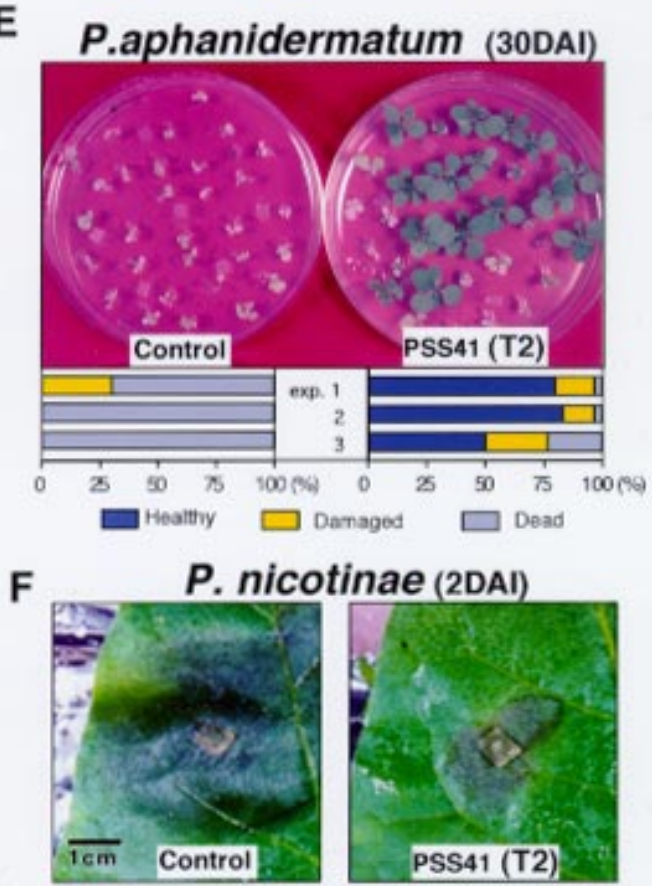

Fig. 4. Enhanced resistance against fungal pathogens in PSS41 line. A, Control (35S::GUS) and PSS41 (right) seedlings inoculated with Rhizoctonia solani. R. solani was inoculated to seedlings of kanamycin-resistant control (35S::GUS) and PSS41 ( $\mathrm{T}_{2}$ ) plants by placing 3-mm-diameter mycelial disks on the medium. Photographs were taken 2 days after inoculation. Bar $=2 \mathrm{~mm}$. B, Cross section of infected cotyledons. Upper panel, cotyledons of 35S::GUS and PSS41 seedlings were fixed and cross-sectioned to $15 \mu \mathrm{m}$ thick at site indicated by arrowhead in (A) after the mycelium was stained by thionin and orange G according to Stougton (1930). Lower panels, boxes in upper panels were expanded. C, Induced accumulation of sarcotoxin by fungal inoculation. Thirty PSS41 seedlings (14 days after sowing) were transplanted to two agar plats. Two days after transplantation, one plate was inoculated with $R$. solani by placing seven mycelial disks on the medium among seedlings. Two days after inoculation, four seedlings from each plate were picked up and subjected to protein gel blotting with anti-sarcotoxin antibody. Non-infected, seedlings in non-inoculated plate; $R$. solani, seedlings from inoculated plate with $R$. solani. D, Enhanced resistance against infection of $R$. solani in PSS 41 seedlings. Thirty seedlings of kanamycin-resistant control (35S::GUS) and PSS41 ( $\mathrm{T}_{2}$ ) plants were transplanted to agar plate containing 1/2 Murashige-Skoog (MS) salt. Two days after transplantation, seven mycelial plugs $(3 \times 3 \mathrm{~mm})$ of $R$. solani were placed on the medium and incubated in a growth chamber. Photograph was taken 15 days after inoculation. Percentages of healthy, damaged, and dead individuals in three independent experiments are indicated at bottom of picture. Healthy, vigorously growing without symptom; Damaged, wilted and/or rotted but color remained green at least in one part; Dead, completely lost green color. E, Enhanced resistance against infection of Pythium aphanidermatum in PSS 41 seedlings. Seven mycelial plugs of $P$. aphanidermatum were placed among seedlings in an agar plate. Photograph was taken 30 days after the inoculation. Percentages of healthy, damaged, and dead individuals in three independent experiments are indicated at bottom of picture. F, Suppressed symptoms by infection of Pseudomonas nicotianae in PSS41 plants. Fully developed leaves of control (35S::GUS) and PSS41 plants $\left(\mathrm{T}_{2}\right) 20 \mathrm{~cm}$ in height were detached and mycelial plugs of $P$. nicotianae were placed on leaf surface. Leaves were then incubated in a moist chamber for 2 days. 
receptor. Fourth, higher plants do not appear to produce antimicrobial peptides with a structure similar to that of sarcotoxin IA. Fifth, sarcotoxin IA appears to have the highest antibacterial activity among cecropin-type, antibactericidal peptides (Nakajima et al. 1987). Sixth, the homologs of sarcotoxin IA were reported in hemolymph of insects, as well as in the intestine of mammals (Lee et al. 1989) and tunicates (Zhao et al. 1997), suggesting the sarcotoxin homologs might play a role in protecting animals from the attack of pathogenic microorganisms. Thus, similar peptides may be present in animal proteins that humans consume daily.

This is the first report to demonstrate that transgenic plants expressing the antimicrobial peptide from insects showed resistance to both fungal and bacterial pathogens. Levels and timing of transgenic expression of the sarcotoxin peptide are important considerations in generating resistant plants against the pathogens. With a modified CaMV promoter that confers constitutive and 10-times-higher expression than the CaMV $35 \mathrm{~S}$ promoter, we previously reported $2 \mu \mathrm{g}$ of sarcotoxin IA per g FW of tobacco leaves of PST10 line (Ohshima et al. 1999). The concentration of sarcotoxin in PST10 leaves is calculated to be $0.5 \mu \mathrm{M}$. Here, we used SA-inducible PR promoter for expression of the peptide in transgenic plants. Sarcotoxin IA was detected at about $0.5 \mu \mathrm{g}$ per $\mathrm{g}$ FW of noninduced leaves and up to $20 \mu \mathrm{g}$ per g FW SA-treated leaves of PSS transgenic line. These correspond to average concentrations of 0.125 and $5 \mu \mathrm{M}$, respectively, in leaves. Thus, we are able to increase by 10 -fold the expression level of sarcotoxin with the SA-inducible PR promoter. The induced level of sarcotoxin is over the minimal bactericidal concentration of the peptide to E. coli $(0.2 \mu \mathrm{M}$; Nakajima et al. 1987) but lower than $\mathrm{IC}_{50}$ for fungal growth $(12.5 \mu \mathrm{M})$. PR1a promoter is effectively activated by pathogen infection and PR proteins accumulate around necrotic lesions (Ohshima et al. 1990). In PSS41 line, the sarcotoxin concentration was elevated to about $2 \mu \mathrm{M} 2$ days after inoculation of $P$. syringae (Fig. 4F). All endogenous tobacco PR proteins are simultaneously induced by necrotic lesion formation in pathogen-infected tissues. Thus, we believe a dual mechanism of resistance occurs in the transgenic PSS lines. The non-induced level of sarcotoxin should inhibit the growth of pathogens at the beginning of infection. Then, the higher induced-level of sarcotoxin peptide in cooperation with PR proteins should restrict the spread of pathogens. We believe simultaneous induction of transgenic sarcotoxin and PR proteins upon pathogen attack would greatly enhance the resistance of host plants.

In this work, sarcotoxin was expressed as a fusion peptide with the signal peptide of PR1a for secretion to intracellular space. Sarcotoxin IA was recovered from the ICF of SAtreated PSS41 leaves, albeit at a low rate (Fig. 1D), while recovery of PR1 proteins was about $50 \%$. The difference in recovery may be accounted for by several reasons. Sarcotoxin is highly cationic (PI 11.6; Matsumoto et al. 1986) while PR1a protein is anionic (PI 4.0; Matsuoka and Ohashi 1984). Sarcotoxin and PR proteins should interact differently to other molecules in the cell wall and intercellular spaces. Sarcotoxin and PR1a protein hold different sensitivity to potential proteases in ICF. Extraction efficiency of sarcotoxin from the leaves of PST10 plant has been reported to improve with a buffer containing 0.5 M NaCl (Ohshima et al. 1999). Barleyleaf-specific thionin, a basic antimicrobial peptide classified to PR-13 (PI 8.7), was reported to associate with cell wall, and a high ionic strength, such as $1.5 \mathrm{M} \mathrm{LiCl}$, was required to solubilize the peptide from cell wall (Bohlman et al. 1988). Thus, once expressed, the sarcotoxin peptide may be correctly secreted outside of the cells, and accumulate in the cell wall and intercellular spaces. A number of pathogens invade though intercellular spaces, and the intercellular spaces and cell walls are the battleground between pathogens and host plants. Accumulation of the antimicrobial peptide in such a part of plants should effectively enhance host resistance to invading pathogens.

The size of immunologically detectable sarcotoxin in transgenic plants was $8.2 \mathrm{kDa}$, probably dimer. When the synthetic sarcotoxin IA peptide was used for protein gel blot analysis, the major signal was found at $4.2 \mathrm{kDa}$ with the minor signal at $8.2 \mathrm{kDa}$ (Fig. 1B). This observation suggests that the peptide may be more stable as a dimer at a lower concentration.

Stability of the target protein in transgenic plants is an important consideration for transgenic studies. Lower than expected levels of the peptides have been reported in bacteria (Derynck et al. 1984) and animal (Yamada et al. 1990) expression systems, compared with mRNA levels, indicating the instability of the peptides in the different host cells. Cecropin was accumulated less than $0.1 \%$ of total protein in transgenic plant (Jaynes et al 1993). When expressed under control of the CaMV 35S promoter, sarcotoxin was not detectable immunologically (data not shown). Sarcotoxin was not stable in the ICFs prepared from several kinds of plants such as tobacco, potato, and cabbage with a half-life around $30 \mathrm{~min}$ (data not shown). Use of a high expression promoter, $\mathrm{El} 2 \Omega$, that confers 20 times higher expression than the $35 \mathrm{~S}$ promoter (Mitsuhara et al. 1996) resulted in immunologically detectable levels of sarcotoxin (Ohshima et al. 1999). The rate of foreign peptide degradation varies by plant species (Owens and Heutte 1997). We have preliminary evidence to indicate that sarcotoxin was more stable in ICFs of rice and soybean leaves than the plant species described above. Expression of the sarcotoxin gene under control of a strong promoter in transgenic rice is now in progress.

Bacterial and fungal pathogens to crops and fruit plants constitute one of many serious threats to the well-being of agriculture. Moreover, liberal use of fungicides and other pesticides to protect plants has contributed to chemical contamination of the environment. It has become increasingly difficult to introduce pest resistance by conventional breeding because genetic resources for resistance genes are limited or in some cases not yet known. We believe one solution to the problem is production of resistant plants by introduction of antimicrobial peptide genes from other kingdoms and accumulation of the peptide in constitutive and disease-inducible manners outside cells, as demonstrated in this report.

\section{MATERIALS AND METHODS}

\section{Plasmid construction.}

A proximal $5^{\prime}$ region of the PR1a promoter ( $-900 \mathrm{bp}$ ) and a sequence encoding a signal peptide were amplified, with primer A (5'-AGTAGA-ATTCTT-AAAACA-CCCTCGAGGATT-TC-3') and B (5'-GGGCTC-TGCAGG-AGTGGGATATT-3') from plasmid pPR- $\gamma$ (Ohshima et al. 1987) the genomic clone of the tobacco PR1a gene. Terminator region 
of the PR1a gene (TPR1a) was obtained with primers $\mathrm{C}\left(5^{\prime}\right.$ ACAGCA-CGTGGT-TAATTG-AGCTCG-AAA-3') and D (5'-TCCCCC-GGGCTG-CAGGAA-TTC-3'). The coding region for mature sarcotoxin 1a (Msarco) was amplified with primers E (5'-CACTCC-TGCAGA-GCCGGT-TGGTTGAAAAAG-ATTGGC-3') and F (5'-TTTCGA-GCTCAATTAACC-ACGTGC-TGTAGC-AGC-3') from pTO19 (Matsumoto et al. 1986). DNA fragment TPR1a and Msarco were fused by recombinant PCR technique (Higuchi 1989). The sequences of PCR products were confirmed after subcloning into pUC plasmid. The chimeric gene with a fulllength, 2.4-kb PR1a promoter and sarcotoxin gene was constructed as described by Sambrook et al. (1982).

A new binary vector was constructed by inversion of the TDNA region of the pTRA415 (Ohshima et al. 1999) by BglII digestion followed by ligation and transformation. Resultant plasmid named pTRA415(R) contains 35S-NPTII marker gene and unique EcoRI site adjacent to right border of TDNA. The PR1a::sarcotoxin chimeric gene was inserted into EcoRI site of pTRA415(R).

\section{Protein gel bolt analysis.}

Preparation of crude extracts and ICF fraction of tobacco leaves were as described by Ohshima et al (1999). Extracts were separated by tricine-SDS gel electrophoresis (Schägger and von Jagow 1987) and transferred to polyvinylidene difluoride (PVDF) membrane by semi-dry electroblotting (KyhseAndersen 1984). Anti-sarcotoxin IA antibody (Ohshima et al. 1999) and anti-PR1a antibody (Niki et al. 1998) were used as a primary antibody with the alkaline phosphatase-conjugated anti-rabbit IgG as a secondary antibody.

\section{Phytopathogenic bacteria and fungi.}

Erwinia carotovora subsp. carotovora (MAFF03-01393) and Pseudomonas syringae pv. tabaci (MAFF03-01075) were supplied by the Gene Bank of the Ministry of Agriculture, Fisheries and Forestry of Japan (MAFF). Rhizoctonia solani for sore shin disease and Pythium aphanidermatum for tobacco damping-off disease were kindly provided by Ryoso Honkura in the Miyagi Prefectural Agricultural Research Center. Phytophthora nicotianae for tobacco black shank disease was provided by Hiroshi Tanaka from Japan Tobacco Inc. (Oyama, Japan).

Bacterial pathogens that were grown on Luria-Bertani (LB) plates were collected and washed three times with sterilized water before inoculation. Fungal pathogens were grown on potato dextrose agar (Difco, Detroit, MI) plate and mycelial disks $(3 \mathrm{~mm}$ in diameter), or mycelial plugs $(3 \times 3 \mathrm{~mm})$ prepared from the plates were used for inoculation.

\section{Antifungal assay of sarcotoxin IA.}

For agar diffusion bioassay, $R$. solani was pre-cultured on potato dextrose agar (Difco) plate. Mycelial disks were cut out from the plate with a sterile cork borer and placed in the center of the test plate mycelial-side down. The plate was incubated in the dark at $28^{\circ} \mathrm{C}$ for 12 to $20 \mathrm{~h}$.

For measurements of electrolyte leakage from mycelium by sarcotoxin, $R$. solani was liquid cultured overnight in potato dextrose broth (Difco). The mycelium, about $3 \mathrm{~cm}$ in diameter, was then washed three times in sterilized water, and incubated for $1 \mathrm{~h}$ in a solution containing various concentration of sarcotoxin at $25^{\circ} \mathrm{C}$. Electric conductivity of the solution was measured with a conductivity detector (CDD-6A; Shimadzu, Kyoto, Japan).

\section{Plant materials and infection by pathogens.}

Leaf disks of tobacco (Nicotiana tabacum cv. Sumsun NN) were transformed by Agrobacterium tumefaciens according to a modified procedure of Horsch et al. (1985). All plants were grown in a growth chamber $\left(16 \mathrm{~h}\right.$ light $/ 8 \mathrm{~h}$ dark at $\left.25^{\circ} \mathrm{C}\right)$.

Fully expanded upper leaves of plants, about $20 \mathrm{~cm}$ in height, were detached and used for infection with pathogens Erwinia carotovora, Pseudomonas syringae, and Phytophthora nicotianae. Resistance against infection of bacterial pathogens was determined as described by Ohshima et al. (1999). Selfed progenies were grown on agar medium containing 1/2 Murashige-Skoog (MS) inorganic salt and kanamycin $(50 \mu \mathrm{g} / \mathrm{ml})$ for 2 weeks. Kanamycin-resistant seedlings were then transplanted to another petri dish and used for treatment with Rhizoctonia solani and Pythium aphanidermatum. Wild-type tobacco plants and tobacco plants transformed with pBI121 (35G::GUS; Jefferson et al. 1987) were used as control.

\section{ACKNOWLEDGMENTS}

This work was supported in part by the fund of COE of Ministry of Science and Technology of Japan. We thank S. Naito of National Food Research Institute of MAFF for suggestions on biometrical analysis, and Y. Gotoh and H. Ochiai for technical assistance.

\section{LITERATURE CITED}

Alexander, D., Goodman, R. M., Gut-Rella, M., Glascock, C., Weymann, K., Friedrich, L., Maddox, D., Ahl-Goy, P., Luntz, T., Ward, E., and Ryals, J. 1993. Increased tolerance to two oomycete pathogens in transgenic tobacco expressing pathogenesis-related protein 1a. Proc. Natl. Acad. Sci. USA 90:7327-7331

Bohlman, H., Clausen, S., Behnke, S., Giese, H., Hiller, C., ReimannPhilipp, U., Schrader, G., Barkholt, V., and Apel, K. 1988. Leafspecific thionins of barley - a novel class of cell wall proteins toxic to plant-pathogenic fungi and possibly involved in the defence mechanism of plants. EMBO J. 7:1559-1565.

Boman, H. G., and Hultmark, D. 1987. Cell-free immunity in insects. Annu. Rev. Microbiol. 41:103-126.

Broglie, K., Chet, I., Holliday, M., Cressman, R., Biddle, P., Knowlton, S., Mauvais, C. J., and Broglie, R. 1991. Transgenic plants with enhanced resistance to the fungal pathogen Rhizoctonia solani. Science 254:1194-1197.

Datta, S., Muthukrishnan, S., and Datta, S. K. 1999. Expression and function of PR-protein genes in transgenic plants. Pages 261-277 in: Pathogenesis-Related Proteins in Plants. S. K. Datta and S. Muthukrishnan, eds. CRC Press, New York.

Derynck, R., Robert, A. B., Winkler, M. E., Chen, E. Y., and Goeddel, D. V. 1984. Human transforming growth factor- $\alpha$ : Precursor structure and expression in E. coli. Cell 38:287-297.

Fukuoka, H., Ogawa, T., Mitsuhara, I., Iwai, T., Isuzugawa, K., Nishizawa, Yoko, Gotoh, Y., Nishizawa, Y., Tagiri, A., Ugaki, M., Ohshima, M., Yano, H., Murai, N., Niwa, Y., Hibi, T., and Ohashi, Y. Agrobacterium-mediated transformation of monocot and dicot plants using the NCR promoter derived from soybean chlorotic mottle virus. Plant Cell Rep. (In press.)

Goodman, R. N., and Novacky, A. J. 1994. The Hypersensitive Reaction in Plants to Pathogens: A resistance Phenomenon. American Phytopathological Society, St. Paul, MN.

Hejzlar, M., Paroubek, M., Semidubsky, V., Sanfánková, M., Hájkova, L., Jerábková, V., Simerková, V., Vestáková, H., Machková, O., Vymolá, F., Jedlickvá, Z., Lochman, O., Lonská, V., Duben, J., 
Neubauer, M., Nádvornik, P., Kutálek, E., Bolchová, S., Bubál, K., Udrzal, J., and Stehlik, J. 1969. Effect of carbenicillin on various biotypes of the genus Proteus. Int. J. Clin. Pharmacol. Ther. Toxicol. (Suppl.) 5:8.

Higuchi, R. 1989. Using PCR to engineer DNA. Pages 61-70 in: PCR Technology. H. A. Erlich, ed. Stockton Press, New York.

Horsch, R. B., Fry, J. E., Hoffman, N. L., Eichholtz, D., Rogers, S. G., and Fraley, R. T. 1985. A simple method for transferring gene into plants. Science 227:1229-1231.

Jaynes, J. M., Nagpala, P., Destéfano-Beltrán, L., Huang, J.-H., Kim, J., Denny, T., and Cetiner, S. 1993. Expression of a cecropin B lytic peptide analog in transgenic tobacco confers enhanced resistance to bacterial wilt caused by Pseudomonas solanacearum. Plant. Sci. 98:43-53.

Jefferson, R. A., Kavanagh, T. A., and Bevan, M. V. 1987. GUS fusions: $\beta$-Glucuronidase as a sensitive and versatile gene fusion marker in higher plants. EMBO J. 6:3901-3907.

Jia, S. R., Xie, Y., Tang, T., Feng, L.-X., Cao, D.-S., Zhao, Y.-L., Yuan, J., Bai, Y.-Y., Jiang, C.-X., and Jaynes, J. M. 1993. Genetic engineering of Chinese potato cultivars by introducing antibacterial polypeptide gene. Pages 208-212 in: Biotechnology in Agriculture. Vol. 15. C. B. You, Z. Chen, and Y. Ding, eds. Kluwer Academic Pub., Dordrecht, The Netherlands.

Kunin, C. M. 1967. A guide to use of antibiotics in patients with renal disease. Ann. Intern. Med. 67:151.

Kyhse-Andersen, J. 1984. Electroblotting of multiple gels: A simple apparatus without buffer tank for rapid transfer of protein from polyacrylamide to nitrocellulose. J. Biochem. Biophys. Methods 10:203-209.

Lee, J. Y., Boman, A., Sun, C. X., Anderson, M., Jornvall, H., Mutt, V., and Boman, H. G. 1989. Antibacterial peptides from pig intestine: Isolation of a mammalian cecropin. Proc. Natl. Acad. Sci. USA 86: 9159-9162.

Matsumoto, N., Okada, M., Takahashi, H., Ming, Q. X., Nakajima, Y., Nakanishi, Y., Komano, H., and Natori, S. 1986. Molecular cloning of a cDNA and assignment of the C-terminal of sarcotoxin IA, a potent antibacterial protein of Sarcophaga peregrina. Biochem. J. 239:717-722.

Matsuoka, M., and Ohashi, Y. 1984. Biochemical and serological studies of pathogenesis-related proteins of Nicotiana species. J. Gen. Virol. 65:2209-2215.

Mitsuhara, I., Ugaki, M., Hirochika, H., Ohshima, M., Murakami, T., Gotoh, Y., Katayose, Y., Nakamura, S., Honkura, R., Nishimiya, S., Ueno, K., Mochizuki, A., Tanimoto, H., Tsugawa, H., Otsuki, Y., and Ohashi, Y. 1996. Efficient promoter cassettes for enhanced expression of foreign genes in dicotyledonous and monocotyledonous plants. Plant Cell Physiol. 37:49-59.

Nakajima, Y., Qu, X. M., and Natori, S. 1987. Interaction between liposomes and sarcotoxin IA, a potent antibacterial protein of Sarcophaga peregrina (flesh fly). J. Biol. Chem. 262:1665-1669.

Niki, T., Mitsuhara, I., Seo, S., Ohtsubo, N., and Ohashi, Y. 1998. Antagonistic effect of salicylic acid and jasmonic acid on the expression of pathogenesis-related (PR) protein genes in wounded mature tobacco leaves. Plant Cell Physiol. 39:500-507.

Okada, M., and Natori, S. 1984. Mode of action of a bactericidal protein induced in the haemolymph of Sarcophaga peregrina (flesh-fly) larvae. Biochem. J. 222:119-124.

Ohshima, M., Itoh, H., Matsuoka, M., Murakami, T., and Ohashi, Y. 1990. Analysis of stress-induced or salicylic acid-induced expression of the pathogenesis-related 1a protein gene in transgenic tobacco. Plant Cell 2:95-106.

Ohshima, M., Matsuoka, M. Yamamoto, N., Tanaka, Y., KanoMurakami, Y., Ozeki, Y., Kato, A., Harada, N., and Ohashi, Y. 1987. Nucleotide sequence of the PR-1 gene of Nicotiana tabacum. FEBS Lett. 225:243-246.

Ohshima, M., Mitsuhara, I., Okamoto, M., Sawano, S., Nishiyama, K., Kaku, H., Natori, S., and Ohashi, Y. 1999. Enhanced resistance to bacterial disease of transgenic tobacco plants overexpressing sarcotoxin IA, a bactericidal peptide of insect. J. Biochem. 125:431-435.

Owens, L. D., and Heutte, T. M. 1997. A single amino acid substitution in the antimicrobial defense protein cecropin B is associated with diminished degradation by leaf intercellular fluid. Mol. Plant-Microbe Interact. 10:525-528.

Sambrook, J., Fritsch, E. F., and Maniatis, T. A. 1989. Molecular Cloning: A Laboratory Manual. Cold Spring Harbor Laboratory, Cold Spring Harbor, NY.

Schägger, H., and von Jagow, G. 1987. Tricine-sodium dodecyl sulfatepolyacrylamide gel electrophoresis for the separation of proteins in the range from 1 to $100 \mathrm{kDa}$. Anal. Biochem. 166:368-379.

Schnetkamp, P. P. M., Kaupp, U. B., and Junge, W. 1981. Interfacial potentials at the disk membranes of isolate intact cattle rod outer segments as a function of the occupation state of the interdiskal cationexchange binding sites. Biochem. Biophys. Acta 642:213-230.

Stougton, R. H. 1930. Thionin and orange G for the differential staining of bacteria and fungi in plant tissue. Ann. Appl. Biol. 17:162-164.

van Hofsten, P., Faye, I., Kockum, K., Lee, J. Y., Xanthopoulos, K. G., Boman, I. A., Boman, H. G., Engstrom, A., Andreu, D., and Merrifield, R. B. 1985. Molecular cloning, cDNA sequencing, and chemical synthesis of cecropin B from Hyalophora cecropia. Proc. Natl. Acad. Sci. USA 82:2240-2243.

van Loon, L. C. 1999. Occurrence and properties of plant pathogenesisrelated protein. Pages 1-20 in: Pathogenesis-Related Proteins in Plants. S. K. Datta and S. Muthukrishnan, eds. CRC Press, New York.

Vierheilig, H., Alt, M., Neuhaus, J.-M., Boller, T., and Wiemken, A. 1993. Colonization of transgenic Nicotiana sylvestris plants, expressing different forms of Nicotiana tabacum chitinase, by the root pathogen Rhizoctonia solani and by the mycorrhizal symbiont Glomus mosseae. Mol. Plant-Microbe Interact. 6:261-264.

Yamada, K., Nakajima, Y., and Natori, S. 1990. Production of recombinant sarcotoxin IA in Bombyx mori cells. Biochem. J. 272:633-636.

Zhao, C., Liaw, L., Lee, I. H., and Lehrer, R. I. 1997. cDNA cloning of three cecropin-like antimicrobial peptides (Styelins) from the tunicate, Styela clava. FEBS Lett. 412:144-148.

Zhu, Q., Maher, E. A., Masoud, S., Dixon, R. A., and Lamb, C. J. 1994. Enhanced protection against fungal attack by constitutive coexpression of chitinase and glucanase genes in transgenic tobacco. Bio/Technology 12:807-812 